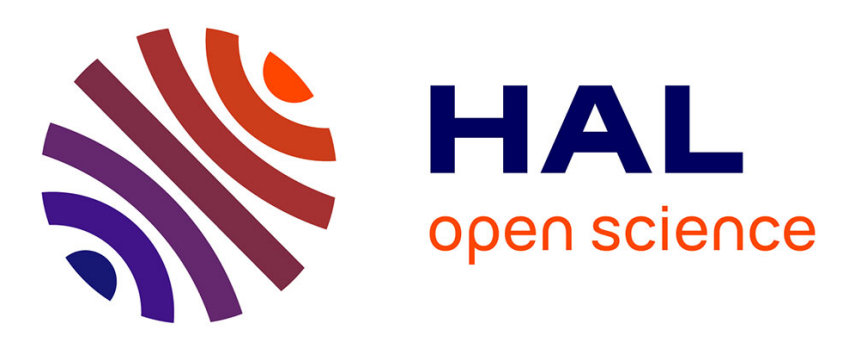

\title{
Identification of boundary pressure field exciting a plate under turbulent flow
}

Nicolas Totaro, Charles Pezerat, Q. Leclere, Fabien Chevillotte, Damien Lecoq

\section{To cite this version:}

Nicolas Totaro, Charles Pezerat, Q. Leclere, Fabien Chevillotte, Damien Lecoq. Identification of boundary pressure field exciting a plate under turbulent flow. FLINOVIA, Nov 2013, Rome, Italy. hal-00999367

\section{HAL Id: hal-00999367 https://hal.science/hal-00999367}

Submitted on 3 Jun 2014

HAL is a multi-disciplinary open access archive for the deposit and dissemination of scientific research documents, whether they are published or not. The documents may come from teaching and research institutions in France or abroad, or from public or private research centers.
L'archive ouverte pluridisciplinaire HAL, est destinée au dépôt et à la diffusion de documents scientifiques de niveau recherche, publiés ou non, émanant des établissements d'enseignement et de recherche français ou étrangers, des laboratoires publics ou privés. 


\section{Identification of boundary pressure field exciting a plate under turbulent flow \\ N. Totaro, C. Pézerat, Q. Leclère, F. Chevillotte, D. Lecoq}

The direct measurement of the wall pressure induced by a turbulent flow on a structure needs the use of flushmounted microphones or the use of specific instrumented panels. For example, estimating the pressure induced by a rearview mirror on an automobile glass is a particularly difficult task. The objective of the present approach is to identify the pressure field by measuring the vibration field of the real structure (the glass for example). This kind of measurements will avoid heavy instrumentation of the structure.

The Force Analysis Technique (FAT) is a method allowing the identification of the force distribution acting on a structure by measuring its velocity field. These measurements are done on a finite different scheme to estimate the spatial derivatives of the equation of motion of the structure. Even if there is no inversion of an illconditioned matrix, the technique is highly sensitive to noise measurements and needs a wavenumber low-pass filtering step or by using an adequate spacing between sensors. One must highlight here that FAT is a local method and that there is no need to know the boundary conditions. FAT only needs the equation of motion of the structure. Until now, FAT has been developed for simple structures such as beams, plates and shells but an extension to the use of finite element method has also been investigated.

FAT has been applied to any kind of excitations (point forces, moments, acoustic diffuse field, injected power, etc) and several experiences have been carried out to test its applicability on detached flow excitations. As an example in Figure 1, the system under study is a simple rectangular plate excited by a turbulent pressure field induced by a rigid cube placed in the flow. The velocity field of the plate was measured by an array of $13 \mathrm{pU}$ probes (on a finite difference scheme) placed in the near-field of the plate at the opposite side of the excitation. The final objective was here to identify the pressure field acting on the plate, which can be compared to a direct measurement of the pressure field measured classically with an instrumented panel (replacing the plate by a rigid panel).
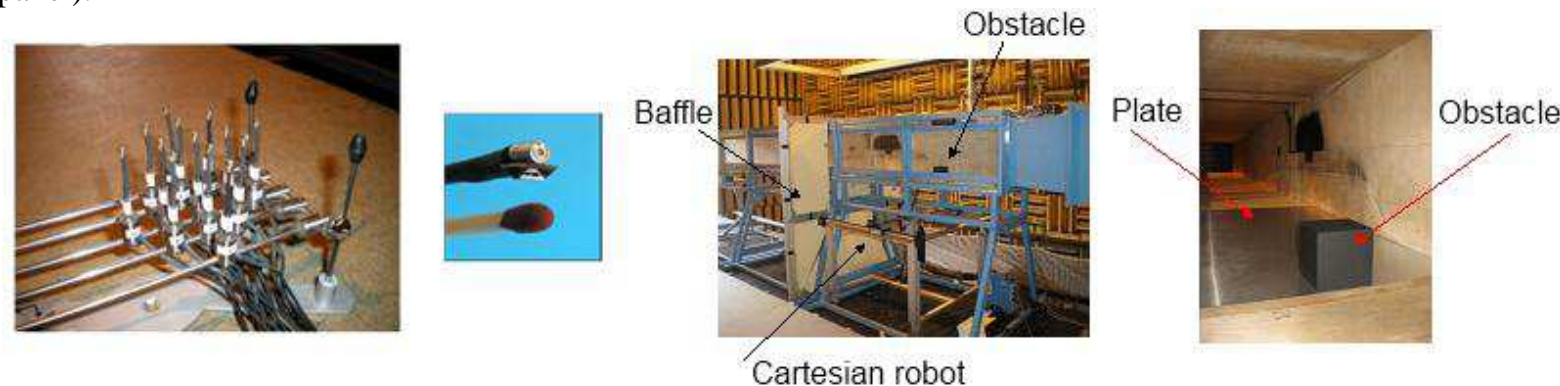

Figure 1 : System under study: a plate excited by a TBL induced by an obstacle. Acoustic measurements in the near-field done by $13 \mathrm{pU}$ probes.

It has been demonstrated that, due to filtering effects of the plate and the finite difference scheme, the convective part of the pressure field can't be identified using FAT. Indeed, identification of force distribution of FAT technique is driven by the spatial sampling of the equation of motion and by the natural wavenumber of the structure. Unfortunately, the convective pick of the turbulent flow is often much higher than the FAT limit of applicability [3].

However, FAT identifies accurately the components of the pressure field which have a wavenumber lower than the natural wavenumber of the plate [2]. This is the case when an acoustic excitation exists. For examples, it has been possible to clearly identify the acoustic resonances of the wind tunnel or to measure precisely the acoustic excitation due to a loudspeaker placed outside the flow, while these acoustic components were completely merged in the aerodynamic pressure exciting the instrumented panel. It has been also shown that for the particular case of a Turbulent Boundary Layer excitation, the acoustic component of the field can be extracted using FAT up to the critical frequency of the plate.

In the last part of the paper, a presentation of the possibility to analyze if the acoustic component is the only one component reconstructed by FAT is done [4]. The analysis is based on the use of several finite schemes, each having its own wavenumber response. Finally, the importance of the choice of finite differences schemes is discussed since they can then be used for the spatial derivative approximation; they serve as regularization when using adequate spacing and can be exploited to analyze the result in the wavenumber domain.

Summarizing, FAT is not able to represent the whole pressure field acting on the plate but only the part that is responsible of noise radiated by the plate and is particularly difficult to measure since it is often small compared to the pressure fluctuations. Since this low-wavenumber component is responsible for the radiated noise, it is of great interest for vehicle manufacturers to quantify it by measurement. 
[1] C. Pézerat, Q. Leclère, N. Totaro, M. Pachebat, Identification of vibration excitations from acoustic measurements using near field acoustic holography and the force analysis technique, JSV 326 (2009), p.540556.

[2] Q. Leclère, C. Pézerat, Vibration source identification using corrected finite difference scheme, JSV 331 (2012), p.1366-1377.

[3] F. Chevillotte, Q. Leclère, N. Totaro, C. Pézerat, P. Souchotte, G. Robert, Identification d'un champ de pression pariétale induit par un écoulement turbulent à partir de mesures vibratoires, CFA 2010, Lyon, France.

[4] D. Lecoq, C. Pézerat, J.-H. Thomas, W. Bi, How an inverse vibration method can be used for the extraction of the acoustic component of a Turbulent Boundary Layer? Internoise 2012, New-York, USA. 